\title{
Analytical Solution for Electroosmotic Consolidation Considering Nonlinear Variation of Soil Parameters
}

\author{
Hui Wu, Ph.D. ${ }^{1}$; Liming Hu, Ph.D., A.M.ASCE ${ }^{2}$; Wengang Qi, Ph.D. ${ }^{3}$; and Qingbo Wen ${ }^{4}$
}

\begin{abstract}
Electroosmotic consolidation can be used as an efficient technique for soft soil improvement. Considering the limitation in previous theories that soil parameters keep constant during electroosmotic consolidation, the nonlinear relationships between soil compressibility, hydraulic and electroosmosis conductivities, and void ratio are incorporated in a one-dimensional model in the present study. The analytical solutions for the ultimate excess pore-water pressure and surface settlement are derived. A comparison between the proposed analytical solutions and traditional theory indicates that the nonlinear variation of hydraulic conductivity results in a larger ultimate excess pore-water pressure, whereas the nonlinear variation of electroosmosis conductivity leads to a smaller one. The effects are more significant for soils with higher compressibility. The nonlinear variation of soil compressibility exhibits remarkable impact on the development of excess pore-water pressure when the nonlinear variations of hydraulic and electroosmosis conductivities are considered. Compared with the ultimate excess pore-water pressure, the impact of nonlinear variations of soil parameters on the ultimate surface settlement is less significant. DOI: 10.1061/ (ASCE)GM.1943-5622.0000821. (C) 2016 American Society of Civil Engineers.
\end{abstract}

Author keywords: Electroosmotic consolidation; Analytical solution; Nonlinear soil parameters; Excess pore-water pressure; Settlement.

\section{Introduction}

Electroosmotic consolidation is a potential technique for soft soil improvement. By applying an external electrical field to a soil mass, the pore water can be moved from anode to cathode along with the electromigration of cations, leading to the consolidation of the treated soil mass. Numerous laboratory experiments and field tests have been conducted to investigate the development of pore-water pressure and settlement during electroosmotic consolidation, and soil properties such as water content and shear strength after the treatment were measured to evaluate the effect of this technique (Bjerrum et al. 1967; Esrig and Gemeinhardt 1967; Lo et al. 1991; Lefebvre and Burnotte 2002; Cherepy and Wildenschild 2003; Glendinning et al. 2007; Jeyakanthan et al. 2011; Wu et al. 2015a; Wu et al. 2016). Since Casagrande (1949) first applied electroosmotic consolidation to improve the stability of fine soils, this technique has been used often in geotechnical engineering including during slope stabilization, soft ground improvement, tailing dewatering, sludge treatment, and so on (Glendinning et al. 2005; Fourie et al. 2007; Zhuang and Wang 2007; Jones et al. 2008; Wu et al.

\footnotetext{
${ }^{1}$ Research Associate, State Key Laboratory of Hydro-Science and Engineering, Dept. of Hydraulic Engineering, Tsinghua Univ., Beijing 100084, P.R. China. E-mail: hui-wu@ mail.tsinghua.edu.cn

${ }^{2}$ Associate Professor, State Key Laboratory of Hydro-Science and Engineering, Dept. of Hydraulic Engineering, Tsinghua Univ., Beijing 100084, P.R. China (corresponding author). E-mail: gehu@tsinghua .edu.cn

${ }^{3}$ Research Associate, Institute of Mechanics, Chinese Academy of Science, Beijing 100190, P.R. China. E-mail: qiwengang@imech.ac.cn

${ }^{4}$ Associate Professor, State Key Laboratory of Hydro-Science and Engineering, Dept. of Hydraulic Engineering, Tsinghua Univ., Beijing 100084, P.R. China. E-mail: wenqb@tsinghua.edu.cn

Note. This manuscript was submitted on April 26, 2016; approved on August 30, 2016; published online on October 4, 2016. Discussion period open until March 4, 2017; separate discussions must be submitted for individual papers. This technical note is part of the International Journal of Geomechanics, (C) ASCE, ISSN 1532-3641.
}

2015b), and various methods have been proposed to improve its efficiency, such as intermittent current, electrode reversal, moving electrode, and a combination of surcharge and vacuum preloading (Shang 1998; Micic et al. 2001; Yoshida et al. 1999; Wu and $\mathrm{Hu}$ 2012; Zhan et al. 2016).

Based on the previous experiment results, many analytical models have been developed to analyze soil behavior submitted to electroosmotic consolidation, and the solutions for pore-water pressure and degree of consolidation are derived. Esrig (1968) coupled the hydraulic and electroosmotic flow in a one-dimensional (1D) model and obtained the analytical solutions for the ultimate pore-water pressure under different boundary conditions. Wan and Mitchell (1976) further investigated the effect of surcharge preloading during electroosmotic consolidation. Following their pioneering work, several analytical solutions have been derived for electroosmotic consolidation considering more complex conditions, including twodimensional (2D) and axisymmetric geometry (Shang 1998; Su and Wang 2003; Wu and $\mathrm{Hu} 2013$ ) and a combination with surcharge preloading and vacuum preloading (Hu et al. 2010; Li et al. 2010; Xu et al. 2011; Wu and $\mathrm{Hu}$ 2012).

One of the main limitations of the previous analytical solutions is the assumption of constant soil parameters during the consolidation process, including mechanical parameters, such as permeability and compressibility, and electrical parameters, such as electroosmosis conductivity. Both the laboratory and field measurements indicated that these soil parameters encountered nonlinear variations during electroosmotic consolidation (Bjerrum et al. 1967; Casagrande 1983; Burnotte et al. 2004; Hu et al. 2012; Zhou et al. 2013; Yuan and Hicks 2013; Hu and Wu 2014; Wu and Hu 2014). Such variations would inevitably affect the development of porewater pressure and surface settlement. Many attempts have been made to derive analytical solutions for traditional 1D consolidation problems considering the nonlinear variations of soil permeability and compressibility (Davis and Raymond 1965; Gibson et al. 1967; Gibson et al. 1990; Xie et al. 2002; Lekha et al. 2003; Indraratna et al. 2005; Geng et al. 2006; Walker and Indraratna 2006; Cai et al. 2007; Hu et al. 2009; Walker et al. 2012; Abuel-Naga and Pender 2012; Zhu and Yin 2012; Hsu and Tsai 2015). However, the 
analytical solution for electroosmotic consolidation with variable soil parameters has seldom been studied.

In this study, the nonlinear variations of soil parameters, including compressibility, hydraulic conductivity, and electroosmosis conductivity, are incorporated in a $1 \mathrm{D}$ electroosmotic consolidation model, and the analytical solutions for the ultimate pore-water pressure and surface settlement are derived. Sensitivity analysis is preformed to investigate the impact of the nonlinear variations of these soil parameters.

\section{Nonlinear Variations of Soil Parameters}

\section{Compressibility and Hydraulic Conductivity}

The nonlinear variations of soil compressibility and hydraulic conductivity are generally described with the following equations (Lekha et al. 2003):

$$
\begin{gathered}
e=e_{0}-C_{\mathrm{c}} \cdot \log \left(\sigma^{\prime} / \sigma_{p}\right) \\
e=e_{0}+M \cdot \log \left(k_{h} / k_{h 0}\right)
\end{gathered}
$$

where $e$ and $e_{0}$ are void ratio and initial void ratio, respectively; $\sigma^{\prime}$ and $\sigma_{p}$ are effective stress and initial effective stress, respectively; $C_{c}$ is the compression index; $k_{h}$ and $k_{h 0}$ are hydraulic conductivity and initial hydraulic conductivity corresponding to $e_{0}$; and $M$ is a factor that reflects the change in hydraulic conductivity that resulted from the change in void ratio.

\section{Electroosmosis Conductivity}

Electroosmosis conductivity $k_{e}$ is defined as the water flow velocity under unit electrical gradient, and several theories have been proposed for quantitative prediction of $k_{e}$. Based on the assumption that the radius of the capillary tube is large compared with the thickness of the diffuse double layer surrounding the clay particles and that all the mobile charge is concentrated near the clay particle layer, Helmholtz-Smoluchowski's large-pore theory proposed that $k_{e}$ was proportional to soil porosity $n$ (Mitchell and Soga 2005)

$$
k_{e}=C \frac{e}{1+e}
$$

According to Deng et al. (2011), the relationship in Eq. (3) can be further transformed to the same form as that for hydraulic conductivity

$$
e=e_{0}+N \cdot \log \left(k_{e} / k_{e 0}\right)
$$

where $k_{e 0}$ is the initial electroosmosis conductivity corresponding to $e_{0}$; and $N$ is a factor that describes the change in electroosmosis conductivity caused by the change in void ratio.

\section{Theoretical Analysis}

Fig. 1 shows a schematic diagram of the 1D model for electroosmotic consolidation with the coupling of a surcharge preloading $p_{0}$. The anode at the bottom of the model is impermeable, and pore water is allowed to flow out from the cathode at the top of the model. With the assumptions developed in the previous studies and considering the nonlinear variations of soil parameters in Eqs. (1),

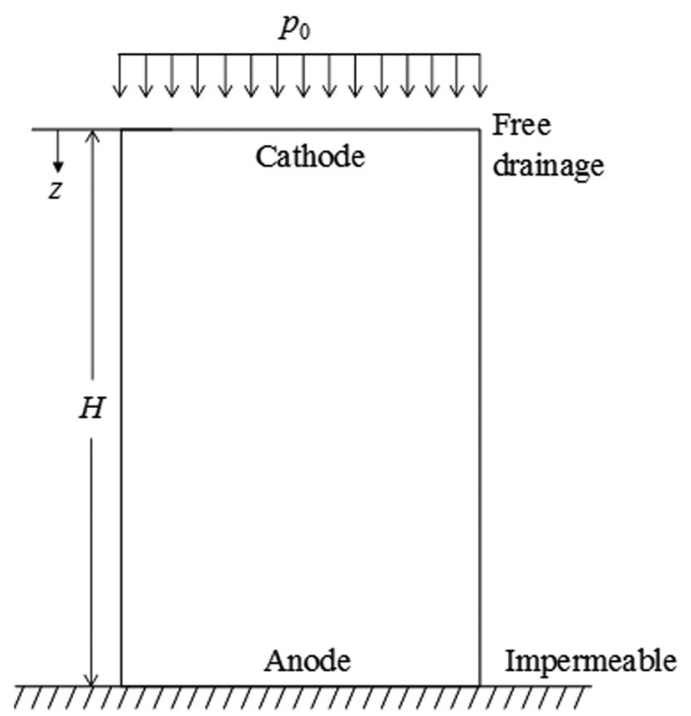

Fig. 1. Diagram of the 1D model for electroosmotic consolidation

(2), and (4), the governing equation for 1D electroosmotic consolidation can be written as (Esrig 1968; Su and Wang 2003; Hu et al. 2010; $\mathrm{Wu}$ and $\mathrm{Hu} 2013$ )

$$
\frac{\partial q}{\partial z}=\frac{\partial}{\partial z}\left(\frac{k_{h}}{\gamma_{w}} \cdot \frac{\partial u}{\partial z}+k_{e} \cdot \frac{\partial V}{\partial z}\right)=m_{v} \frac{\partial u}{\partial t}
$$

where $q$ denotes the pore-water flow; $\gamma_{w}=$ unit weight of water; $u=$ excess pore-water pressure; $V=$ applied voltage; and $m_{v}$ is the coefficient of volume compressibility. At the end of electroosmotic consolidation, the pore-water flow caused by electroosmosis from the anode to cathode is exactly balanced by that caused by the hydraulic gradient from the cathode to anode. Therefore, the distribution of the excess pore-water pressure becomes stable, and Eq. (5) can be simplified as

$$
\frac{\partial}{\partial z}\left(\frac{k_{h}}{\gamma_{w}} \cdot \frac{\partial u_{\mathrm{ult}}}{\partial z}+k_{e} \cdot \frac{\partial V}{\partial z}\right)=0
$$

where $u_{\text {ult }}$ denotes the excess pore-water pressure at the end of electroosmotic consolidation. Considering the boundary condition that the pore-water flow $q$ is 0 at the anode, the following equation can be obtained:

$$
\frac{k_{h}}{\gamma_{w}} \cdot \frac{\partial u_{\mathrm{ult}}}{\partial z}+k_{e} \cdot \frac{\partial V}{\partial z}=0
$$

Further simplifying Eq. (7) by making the substitutions $W_{\text {ult }}=$ $u_{\mathrm{ult}} / p_{0}$ and $Z=z / H$

$$
\frac{\partial W_{\mathrm{ult}}}{\partial Z}+\frac{k_{e} \cdot \gamma_{w}}{k_{h} \cdot p_{0}} \cdot \frac{\partial V}{\partial Z}=0
$$

According to Eqs. (1), (2), and (4), $k_{h}$ and $k_{e}$ can be expressed as

$$
\begin{aligned}
\frac{k_{h}}{k_{h 0}} & =\left(\frac{\sigma^{\prime}}{\sigma_{p}}\right)^{-C_{c} / M}=\left(\frac{\sigma_{p}+p_{0}-u_{\mathrm{ult}}}{\sigma_{p}}\right)^{-C_{c} / M} \\
& =\left[\left(1+\frac{p_{0}}{\sigma_{p}}\right) \cdot\left(1-\beta W_{\mathrm{ult}}\right)\right]^{-C_{c} / M}
\end{aligned}
$$




$$
\begin{aligned}
\frac{k_{e}}{k_{e 0}} & =\left(\frac{\sigma^{\prime}}{\sigma_{p}}\right)^{-C_{c} / N}=\left(\frac{\sigma_{p}+p_{0}-u_{\mathrm{ult}}}{\sigma_{p}}\right)^{-C_{c} / N} \\
& =\left[\left(1+\frac{p_{0}}{\sigma_{p}}\right) \cdot\left(1-\beta W_{\mathrm{ult}}\right)\right]^{-C_{c} / N}
\end{aligned}
$$

in which $\beta=\left(p_{0} / \sigma_{p}\right) /\left(1+p_{0} / \sigma_{p}\right)$.

Substituting Eqs. (9) and (10) into Eq. (8), the following equation is obtained:

$$
\frac{\partial W_{\mathrm{ult}}}{\partial Z}=-\frac{k_{e 0} \cdot \gamma_{w}}{k_{h 0} \cdot p_{0}} \cdot \frac{\partial V}{\partial Z} \cdot\left[\left(1+\frac{p_{0}}{\sigma_{p}}\right) \cdot\left(1-\beta W_{\mathrm{ult}}\right)\right]^{C_{c} / M-C_{c} / N}
$$

A new variable $A$ is defined as

$$
A=\left(1-\beta W_{\mathrm{ult}}\right)^{1+C_{c} / N-C_{c} / M}
$$

The following equation is then obtained:

$$
\frac{\partial A}{\partial Z}=-\beta \cdot\left(1+\frac{C_{c}}{N}-\frac{C_{c}}{M}\right) \cdot\left(1-\beta W_{\mathrm{ult}}\right)^{C_{c} / N-C_{c} / M} \frac{\partial W_{\mathrm{ult}}}{\partial Z}
$$

Substituting Eq. (11) into Eq. (13)

$$
\frac{\partial A}{\partial Z}=-\beta \cdot\left(1+\frac{C_{c}}{N}-\frac{C_{c}}{M}\right) \cdot\left(1+\frac{p_{0}}{\sigma_{p}}\right)^{C_{c} / M-C_{c} / N} \cdot \frac{k_{e 0} \cdot \gamma_{w}}{k_{h 0} \cdot p_{0}} \cdot \frac{\partial V}{\partial Z}
$$

The voltage $V$ is assumed to be linear distributed along the $z$ direction and independent of time; therefore, $\partial V / \partial z$ can be replaced by the electrical field intensity $E$

$$
\frac{\partial V}{\partial z}=E \Rightarrow \frac{\partial V}{\partial Z}=E \cdot H
$$

The term on the right side of Eq. (14) is independent of $Z$ and $t$, and a parameter $B_{0}$ is used to represent the term to simplify the following derivation. As a result, Eq. (14) can be rewritten as

$$
\begin{aligned}
\frac{\partial A}{\partial Z}=- & \beta \cdot\left(1+\frac{C_{c}}{N}-\frac{C_{c}}{M}\right) \cdot\left(1+\frac{p_{0}}{\sigma_{p}}\right)^{C_{c} / M-C_{c} / N} \\
& \cdot \frac{k_{e 0} \cdot \gamma_{w}}{k_{h 0} \cdot p_{0}} \cdot E \cdot H=B_{0}
\end{aligned}
$$

Integrating Eq. (16) in the Z-direction and considering the boundary condition that both the excess pore-water pressure and voltage are 0 at the cathode, the solution for $W_{\text {ult }}$ can be obtained

$$
W_{\mathrm{ult}}=\frac{1}{\beta} \cdot\left[1-\left(1+B_{0} \cdot Z\right)^{1 /\left(1+\frac{C_{c}}{N}-\frac{C_{c}}{M}\right)}\right]
$$

Therefore, the ultimate pore-water pressure $u_{\mathrm{ult}}$ can be derived as

$$
u_{\mathrm{ult}}=\frac{p_{0}}{\beta} \cdot\left[1-\left(1+B_{0} \cdot Z\right)^{1 /\left(1+\frac{C_{c}}{N}-\frac{C_{c}}{M}\right)}\right]
$$

With Eq. (18), the distribution of the ultimate excess pore water can be analyzed. When the values of $M$ and $N$ approach infinity, the hydraulic conductivity and electroosmosis conductivity keep constant during the consolidation process. When $N=M$, the ratio between $k_{h}$ and $k_{e}$ is constant, indicating that the effect of the decrease in $k_{h}$ on the development of excess pore-water pressure is balanced by the effect of the decrease in $k_{e}$. In both cases, the analytical solution for the ultimate excess pore-water pressure degrades to the equation proposed by Esrig (1968)

$$
u_{\mathrm{ult}}=-\frac{k_{e 0} \cdot \gamma_{w}}{k_{h 0}} \cdot E \cdot z
$$

\section{Discussion}

\section{Effects of the Nonlinear Variations of Soil Parameters}

With the proposed analytical solution, the effects of the nonlinear variations of soil parameters can be analyzed. The basic parameters used in the following analysis are listed in Table 1.

To examine the effect of the nonlinear variation of compressibility, the values of $M$ and $N$ are set to be infinite; thus, the ultimate pore-water pressure can be calculated with Eq. (18), which indicates that the nonlinear variation of compressibility has no impact on the development of pore-water pressure. To analyze the effect of the nonlinear variation of hydraulic conductivity, the value of $M$ is varied in the range of 0.8 to 50 , whereas the value of $C_{c}$ is set to be 0.4 , and the value of $N$ is set to be 100 to eliminate the effect of the nonlinear variation of electroosmosis conductivity. Similarly, the value of $N$ is varied in the range of 1-50 to analyze the effect of the nonlinear variation of electroosmosis conductivity, whereas the values of $C_{c}$ and $M$ are set to be 0.4 and 100, respectively. Figs. 2 and 3 compare the distributions of the ultimate excess pore-water pressure obtained from the traditional theory by Esrig (1968) and that from the present study with the consideration of the nonlinear variations of hydraulic and electroosmosis conductivities, respectively. The nonlinear variation of $k_{h}$ leads to a lager ultimate excess pore-water pressure, whereas the nonlinear variation of $k_{e}$ causes a smaller one. With the increase in the values of $M$ and $N$, the effect of the nonlinear variations of $k_{h}$ and $k_{e}$ decreases gradually as anticipated, and the ultimate excess pore-water distribution becomes almost the same as the result from Esrig (1968) when the values of $M$ and $N$ exceed 50.

The distribution of the ultimate excess pore-water pressure for various $C_{c}$ with different combinations of constant values of $M$ and $N$ is shown in Fig. 4. In terms of equal values of $M$ and $N$, the

Table 1. Basic Parameters for Electroosmotic Consolidation in the Analytical Model

\begin{tabular}{lc}
\hline Parameter & Value \\
\hline Unit weight of water $\left[\gamma_{\mathrm{sat}}\left(\mathrm{kN} / \mathrm{m}^{3}\right)\right]$ & 10 \\
Initial hydraulic conductivity $\left[k_{h 0}(\mathrm{~m} / \mathrm{s})\right]$ & $2 \times 10^{-8}$ \\
Initial electroosmosis conductivity $\left[k_{e 0}\left(\mathrm{~m}^{2} \cdot \mathrm{s}^{-1} \cdot \mathrm{V}^{-1}\right)\right]$ & $2 \times 10^{-9}$ \\
Surcharge preloading $\left[p_{0}(\mathrm{kPa})\right]$ & 50 \\
Initial effective stress $\left[\sigma_{p}(\mathrm{kPa})\right]$ & 10 \\
Initial void ratio $\left(e_{0}\right)$ & 2.0 \\
Initial coefficient of compressibility $\left[a_{0}\left(\mathrm{MPa}^{-1}\right)\right]$ & 17.4 \\
Compressibility index $\left(C_{c}\right)$ & 0.4 \\
$M$ & 2 \\
$N$ & 8 \\
Applied voltage $\left[V_{0}(\mathrm{~V})\right]$ & 40 \\
Model height $[H(\mathrm{~m})]$ & 1 \\
\hline
\end{tabular}




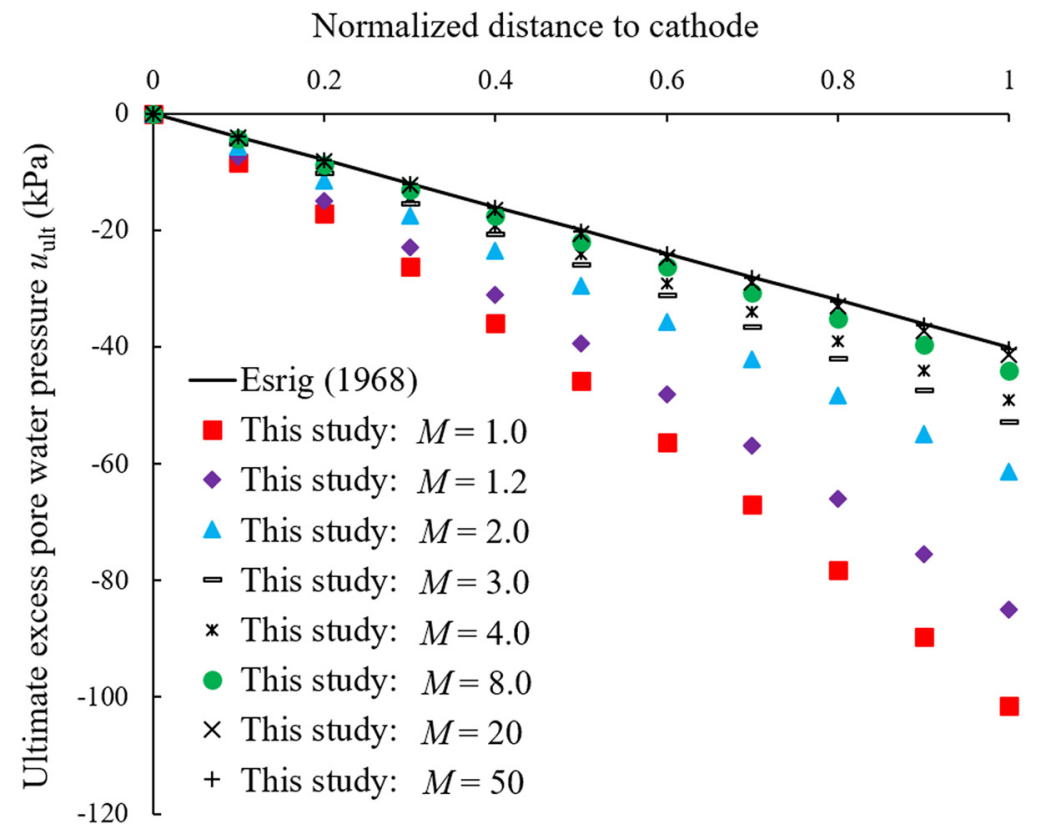

Fig. 2. Effect of the nonlinear variation of hydraulic conductivity on the ultimate excess pore-water pressure

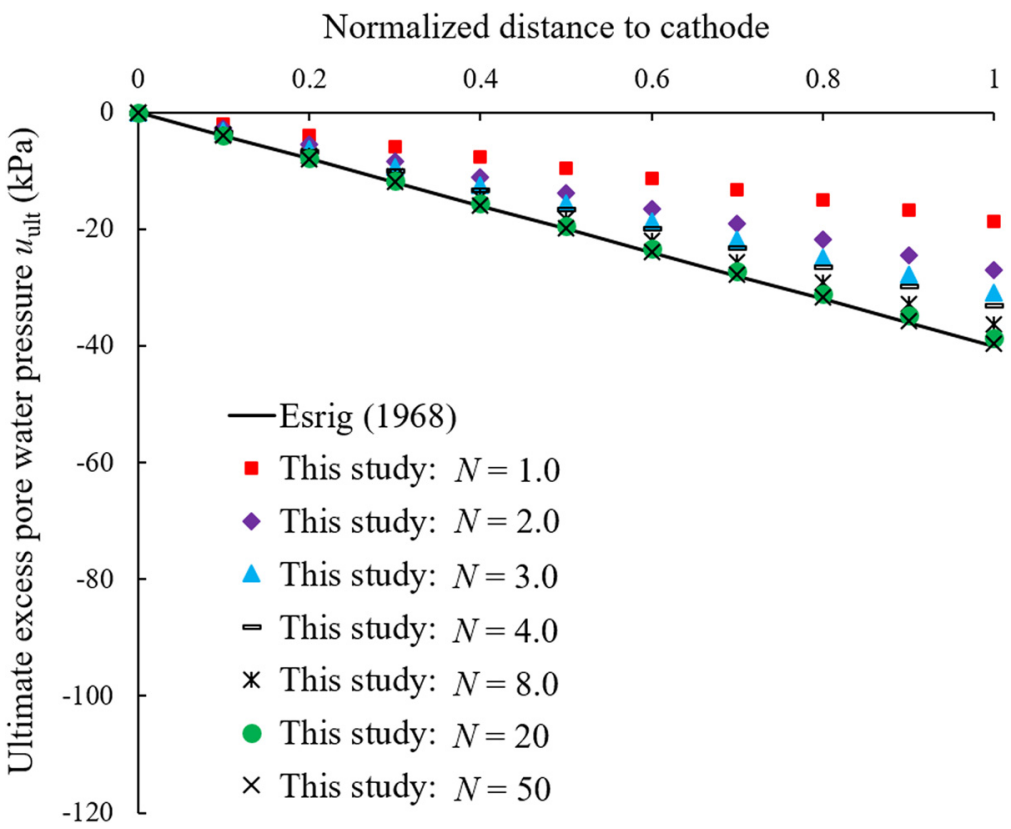

Fig. 3. Effect of the nonlinear variation of electroosmosis conductivity on the ultimate excess pore-water pressure

increase in the ultimate pore-water pressure due to the nonlinear variation of $k_{h}$ is exactly balanced by the decrease caused by the nonlinear variation of $k_{e}$. As such, the nonlinear variation of compressibility exhibits no impact on the ultimate pore-water pressure. However, the effect of the nonlinear variation of compressibility becomes significant when the nonlinear variations of $k_{h}$ and $k_{e}$ are considered, and the values of $M$ and $N$ are different (Fig. 4). For the condition with $M<N$, the effect of the nonlinear variation of $k_{h}$ is more significant than that of $k_{e}$, and the ultimate pore-water pressure is larger than the result from Esrig (1968) and vice versa. The effect of the nonlinear variations of soil parameters increases with the increase in $C_{c}$ for all the examined combinations of $M$ and $N$. When
$C_{c}$ is lower than 0.2 , the results of the present study generally are no different from those of Esrig (1968). With the increase in $C_{c}$, the ultimate excess pore-water pressure increases when $M<N$ and decreases when $M>N$. According to the relationships between void ratio and soil parameters, the nonlinear variation of soil compressibility influences the distribution of the ultimate excess pore-water pressure by affecting the change in void ratio and further influences the variation of $k_{h}$ and $k_{e}$. Therefore, the effect of the nonlinear variations of soil parameters is more significant for high-compressible soil than that for low-compressible soil.

The effects of the nonlinear variations of $k_{h}$ and $k_{e}$ are further displayed in Figs. 5 and 6, which plot the distributions of the 


\section{Normalized distance to cathode}

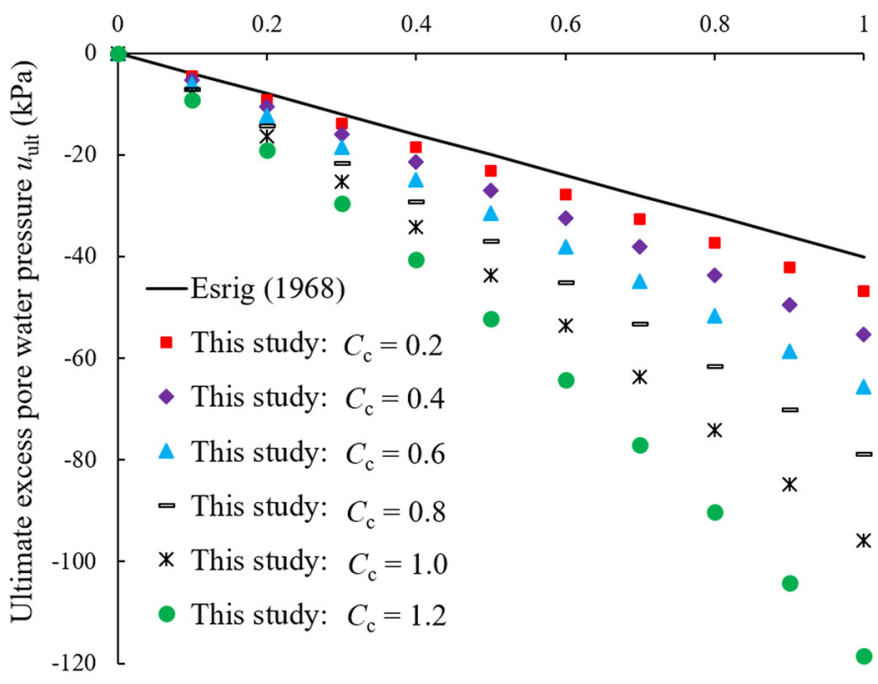

(a)

Normalized distance to cathode

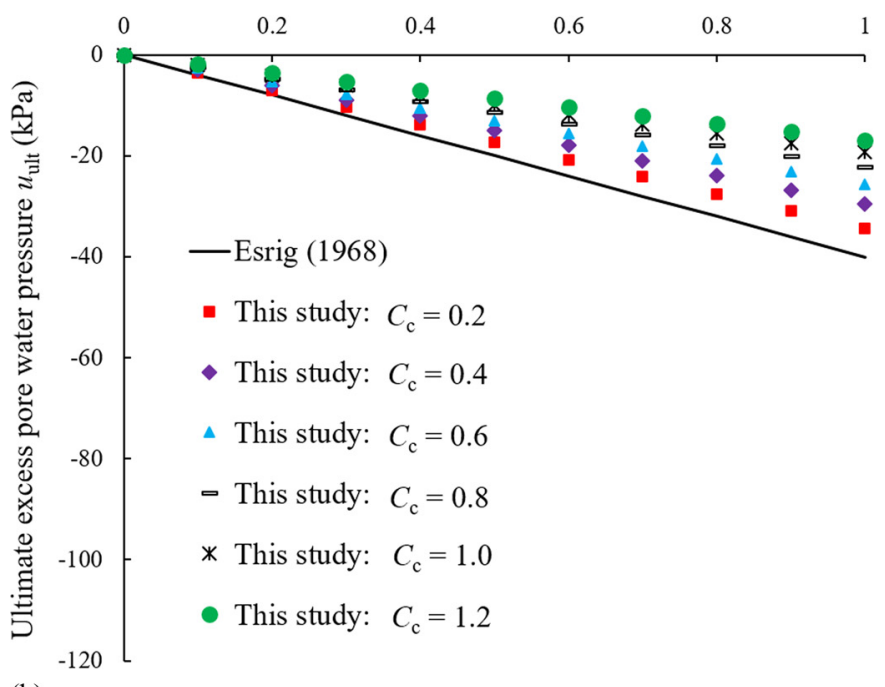

(b)

Fig. 4. Effect of the nonlinear variation of soil compressibility on the ultimate excess pore-water pressure: (a) $M=2.0, N=8.0$; (b) $M=8.0$, $N=2.0$

ultimate excess pore-water pressure for various $M$ with $N=8, C_{c}=$ 0.4 and for various $N$ with $M=2, C_{c}=0.4$, respectively. The calculated ultimate excess pore-water pressure is larger than the result of Esrig (1968) when $M<N$ approaches the same when $M=N$ and finally becomes smaller when $M>N$.

\section{Ultimate Surface Settlement}

The ultimate surface settlement $s_{\text {ult }}$ can be calculated with the following equation:

$$
\begin{aligned}
s_{\mathrm{ult}} & =\int_{0}^{H} \frac{e_{0}-e}{1+e_{0}} d z=\int_{0}^{H} \frac{C_{c} \cdot \log \left(\sigma_{\mathrm{ult}}^{\prime} / \sigma_{p}\right)}{1+e_{0}} d z \\
& =\int_{0}^{H} \frac{C_{c} \cdot \log \left[\left(\sigma_{p}+p_{0}-u_{\mathrm{ult}}\right) / \sigma_{p}\right]}{1+e_{0}} d z
\end{aligned}
$$

where $\sigma^{\prime}$ ult denotes the effective stress at the end of the consolidation process.

Therefore, $s_{\text {ult }}$ for the theory of Esrig (1968) and the present study can be obtained by substituting Eqs. (19) and (18) into Eq. (20), respectively. For the theory of Esrig (1968), $s_{\text {ult }}$ can be derived as

$$
\begin{aligned}
& s_{\mathrm{ult}}=\int_{0}^{H} \frac{e_{0}-e}{1+e_{0}} d z=\int_{0}^{H} \frac{C_{c} \cdot \log \left[\left(\sigma_{p}+p_{0}+\frac{k_{e 0} \cdot \gamma_{w}}{k_{h 0}} \cdot E \cdot z\right) / \sigma_{\mathrm{p}}\right]}{1+e_{0}} d z \\
& =\frac{C_{c}}{2.3 \cdot\left(1+e_{0}\right)}\left\{H \cdot\left[\ln \left(1+\frac{p_{0}}{\sigma_{p}}+\frac{k_{e} \gamma_{w} E H}{k_{h} \sigma_{p}}\right)-1\right]\right. \\
& \left.+\frac{k_{h} \sigma_{p}\left(1+\frac{p_{0}}{\sigma_{p}}\right)}{k_{e} \gamma_{w} E} \cdot\left[\ln \left(1+\frac{p_{0}}{\sigma_{p}}+\frac{k_{e} \gamma_{w} E H}{k_{h} \sigma_{p}}\right)-\ln \left(1+\frac{p_{0}}{\sigma_{p}}\right)\right]\right\}
\end{aligned}
$$

For the present study, $s_{\text {ult }}$ can be expressed as

$$
\begin{aligned}
s_{\mathrm{ult}}= & \int_{0}^{H} \frac{e_{0}-e}{1+e_{0}} d z=\int_{0}^{H} \frac{C_{c} \cdot \log \left[\left(\sigma_{p}+p_{0}-W_{\mathrm{ult}} \cdot p_{0}\right) / \sigma_{p}\right]}{1+e_{0}} d z \\
= & \frac{C_{c}}{1+e_{0}} \int_{0}^{H} \log \left\{1+\frac{p_{0}}{\sigma_{p}}-\frac{p_{0}}{\sigma_{p} \cdot \beta}\right. \\
& \left.\cdot\left[1-\left(1+B_{0} \cdot \frac{z}{H}\right)^{1 /\left(1+\frac{C_{c}}{N}-\frac{C_{c}}{M}\right)}\right]\right\} d z
\end{aligned}
$$

However, this integral is highly related to the value of $1 /\left(1+C_{c} / N-C_{c} / M\right)$ and cannot be expressed by elementary functions for the values of $C_{c}, M$, and $N$ considered in this study. Therefore, an approximate method is proposed to calculate $s_{\mathrm{ult}}$ through the average coefficient of compressibility at the middle of the model as follows:

$$
s_{\mathrm{ult}}=\int_{0}^{H} \frac{e_{0}-e}{1+e_{0}} d z=\int_{0}^{H} \frac{a_{m} \cdot\left(\sigma_{p}+p_{0}-W_{\mathrm{ult}} \cdot p_{0}-\sigma_{p}\right)}{1+e_{0}} d z
$$

where $a_{m}$ is the average coefficient of compressibility at the middle of the model, and can be written as

$$
\begin{aligned}
a_{m}= & \frac{C_{c} \cdot \log \left[\left(\sigma_{p}+p_{0}-\left.W_{\mathrm{ult}}\right|_{z=H / 2} \cdot p_{0}\right) / \sigma_{p}\right]}{\left(\sigma_{p}+p_{0}-\left.W_{\mathrm{ult}}\right|_{z=H / 2} \cdot p_{0}-\sigma_{p}\right)} \\
= & \frac{C_{c} \cdot \log \left\{1+\frac{p_{0}}{\sigma_{p}}-\frac{p_{0}}{\sigma_{p} \beta}\left[1-\left(1+\frac{C_{0}}{2}\right)^{1 /\left(1+\frac{C_{c}}{N}-\frac{C_{c}}{M}\right)}\right]\right\}}{p_{0}-\frac{p_{0}}{\beta} \cdot\left[1-\left(1+\frac{C_{0}}{2}\right)^{1 /\left(1+\frac{C_{c}}{N}-\frac{C_{c}}{M}\right)}\right]}
\end{aligned}
$$

Substituting Eq. (24) into Eq. (23), an approximate analytical solution of $s_{\text {ult }}$ for the present study can be obtained 
Normalized distance to cathode

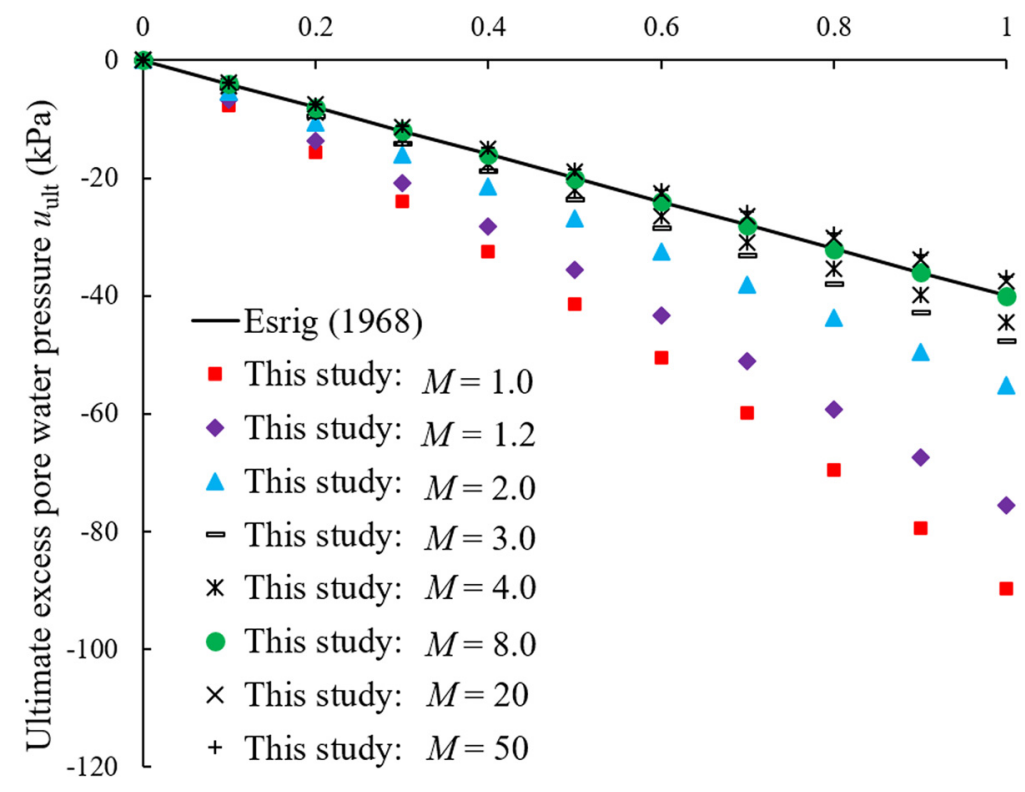

Fig. 5. Effect of the nonlinear variation of hydraulic conductivity on the ultimate excess pore-water pressure with $N=8.0, C_{c}=0.4$

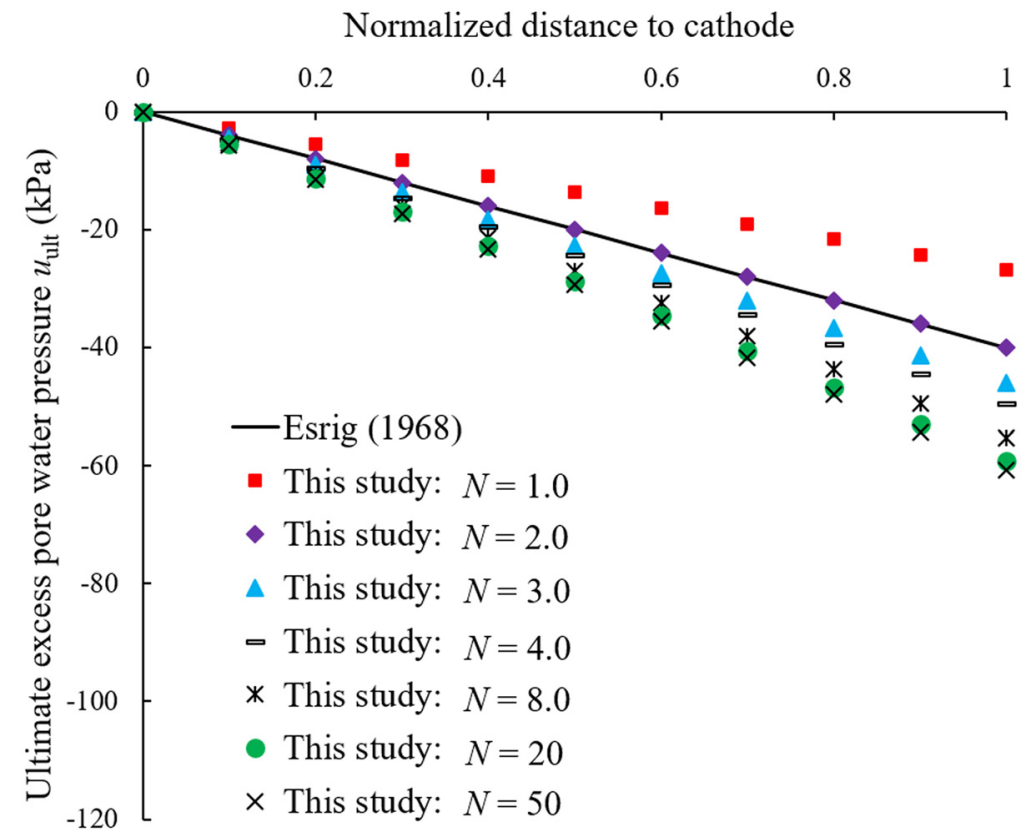

Fig. 6. Effect of the nonlinear variation of electroosmosis conductivity on the ultimate excess pore-water pressure with $M=2.0, C_{c}=0.4$

$$
\begin{aligned}
s_{\mathrm{ult}}= & \frac{a_{m}}{1+e_{0}} \cdot\left\{\left(p_{0}-\frac{p_{0}}{\beta}\right) \cdot H+\frac{p_{0} \cdot H}{\beta \cdot C_{0}} \cdot \frac{1+\frac{C_{c}}{N}-\frac{C_{c}}{M}}{2+\frac{C_{c}}{N}-\frac{C_{c}}{M}}\right. \\
& \left.\cdot\left[\left(1+C_{0}\right)^{\frac{2+\frac{C_{c}}{N}-\frac{C_{c}}{M}}{1+\frac{C_{c}}{N}-\frac{C_{c}}{M}}}-1\right]\right\}
\end{aligned}
$$

To verify this approximate analytical solution, the integral in Eq. (22) is estimated by the numerical integration adopting the Newton-Cotes formula and then compared with the results of Eq. (25).
Figs. 7 and 8 display the ratio between $s_{\text {ult }}$ and $H$ calculated through the Newton-Cotes formula and $a_{m}$ [i.e., Eq. (25)] for various $C_{c}, M$, and $N$, respectively. Both the conditions with $M<N$ and $M>N$ are analyzed, and the results from the theory by Esrig (1968) [i.e., Eq. (20)] are also plotted for comparison. As shown in Figs. 7 and 8 , the results calculated from $a_{m}$ coincide well with that obtained from the Newton-Cotes formula, indicating that Eq. (25) can be used to estimate the ultimate surface settlement. The nonlinear variation of soil parameters presents a similar but smaller impact on $s_{\text {ult }}$ than that on $u_{\text {ult }}$ because soil compressibility decreases (increases) with the increase (decrease) in the value of the negative excess pore-water pressure. When $M<N$, the calculated $s_{\mathrm{ult}}$ from 


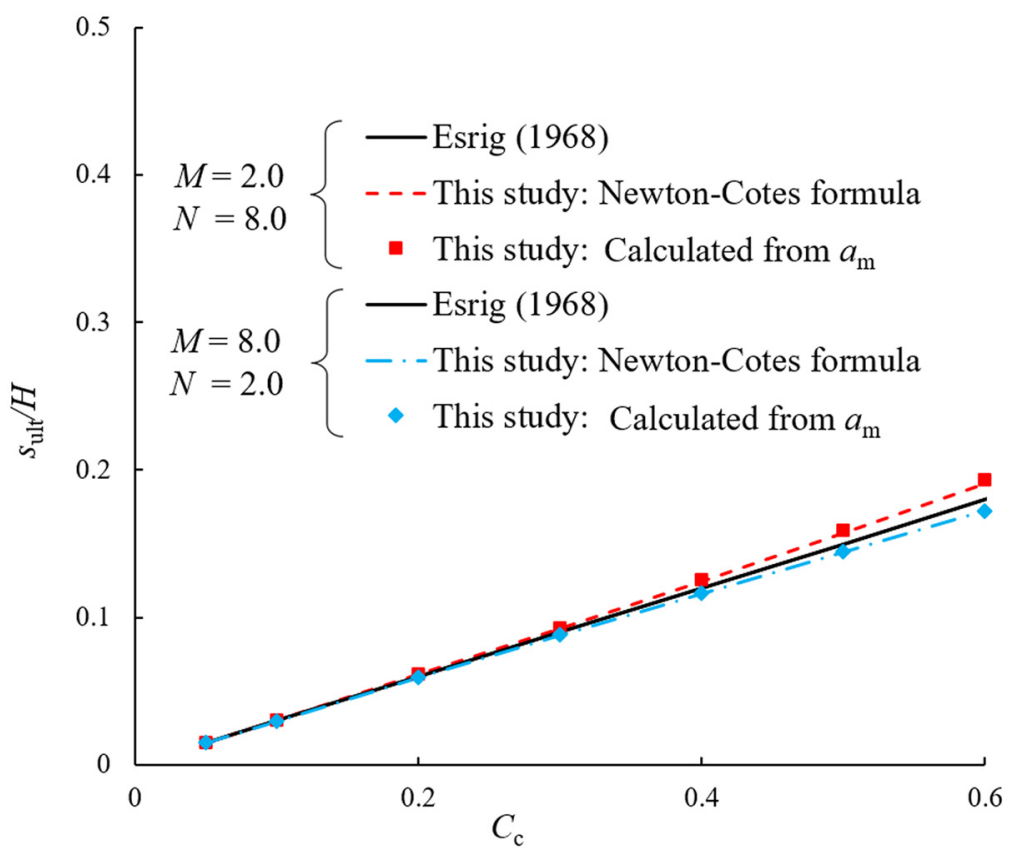

Fig. 7. Comparison of the ultimate surface settlement for various soil compressibilities

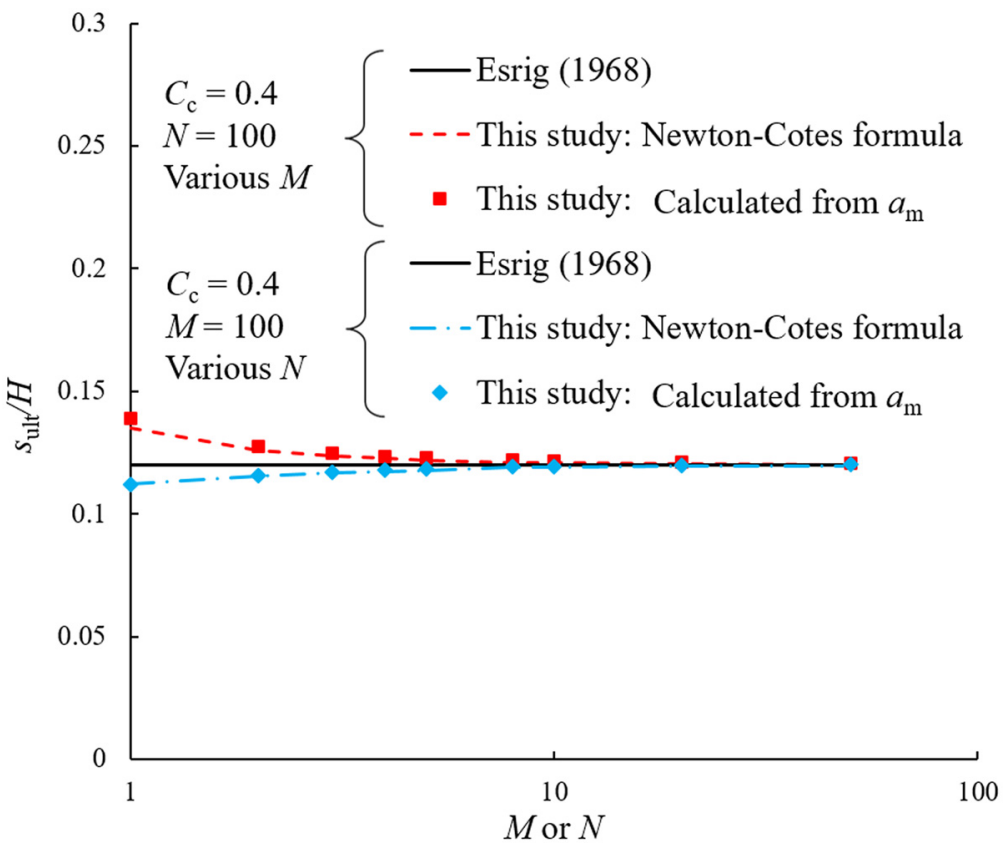

Fig. 8. Comparison of the ultimate surface settlement for various $M$ and $N$

this study is larger than that from Esrig (1968), whereas when $M>N, s_{\text {ult }}$ from this study is smaller than that from Esrig (1968). The effect of the nonlinear variations of soil parameters increases with the increase in $C_{c}$, and is reduced by the increase in the values of $M$ and $N$.

Based on the derived analytical solutions, both the situations that $M<N$ and $M>N$ are examined in the previously mentioned analysis about the ultimate excess pore-water pressure and surface settlement. In fact, many previous studies have investigated the change of hydraulic and electroosmosis conductivities with the change in void ratio. Meegoda et al. (1989) and Hu et al. (2012) indicated that the hydraulic conductivity could be derived as a linear function of $e^{3} /(1+e)$, whereas Mitchell and Soga (2005) reported that the electroosmosis conductivity was proportional to soil porosity $n$ [i.e., $e /$ $(1+e)]$. According to the earlier studies, the electroosmotic conductivity is much less sensitive to the change in void ratio compared with the hydraulic conductivity, which means that the value of $M$ is generally smaller than that of $N$. The previously mentioned scenario of $M<N$ is more common in practical cases. Moreover, the values of $M$ and $N$ can be determined from laboratory tests prior to the application of the proposed analytical solutions for the prediction of the excess pore-water pressure and surface settlement. 


\section{Summary and Conclusions}

The nonlinear relationships between void ratio and soil compressibility, hydraulic conductivity, and electroosmosis conductivity are incorporated in a $1 \mathrm{D}$ electroosmotic consolidation model. Analytical solutions for the ultimate excess pore-water pressure and surface settlement are derived, with which the effects of the nonlinear variations of soil parameters are analyzed. The following conclusions are obtained.

The nonlinear variation of hydraulic conductivity leads to a larger ultimate excess pore-water pressure, whereas the nonlinear variation of electroosmosis conductivity causes a smaller one. Their effects decrease with the decrease in the sensitivity of hydraulic and electroosmosis conductivities to the change in void ratio. Generally, the effects of the nonlinear variations of soil parameters are more significant for soils with higher compressibility.

When the hydraulic and electroosmosis conductivities are assumed to be constant, the nonlinear variation of soil compressibility has no impact on the ultimate excess pore-water pressure. However, its effect becomes remarkable when the nonlinear variations of hydraulic and electroosmosis conductivities are considered, especially for soil with high compressibility.

The nonlinear variations of soil parameters exhibit a smaller impact on the ultimate surface settlement compared with the impact on the ultimate excess pore-water pressure. An approximate analytical solution is proposed to calculate the ultimate surface settlement through the average coefficient of compressibility at the middle of the model. The effectiveness of the approximate analytical solution is verified by comparing with the results from the numerical integration adopting the Newton-Cotes formula.

\section{Acknowledgments}

Financial support from the National Natural Science Foundation of China (Projects 51579132 and 51323014), the Ministry of Education (Project THZ-02-2), and the China Postdoctoral Science Foundation (Grant 2015M581104) are gratefully acknowledged.

\section{Notation}

The following symbols are used in this paper:

$A=$ variable related to ultimate excess pore-water pressure;

$a_{m}=$ average coefficient of compressibility at the middle of the model;

$B_{0}=$ calculating factor for ultimate excess pore-water pressure;

$C_{c}=$ compression index;

$E=$ electrical intensity;

$H=$ height of the model;

$k_{e}, k_{e 0}=$ electroosmosis conductivity and initial electroosmosis conductivity;

$k_{h}, k_{h 0}=$ hydraulic conductivity and initial hydraulic conductivity;

$M, N=$ factors describing the change in hydraulic and electroosmosis conductivities resulted from the change in void ratio;

$m_{v}=$ coefficient of volume compressibility;

$p_{0}=$ surcharge preloading;

$q=$ pore-water flow during electroosmotic consolidation;

$s_{\mathrm{ult}}=$ ultimate surface settlement;

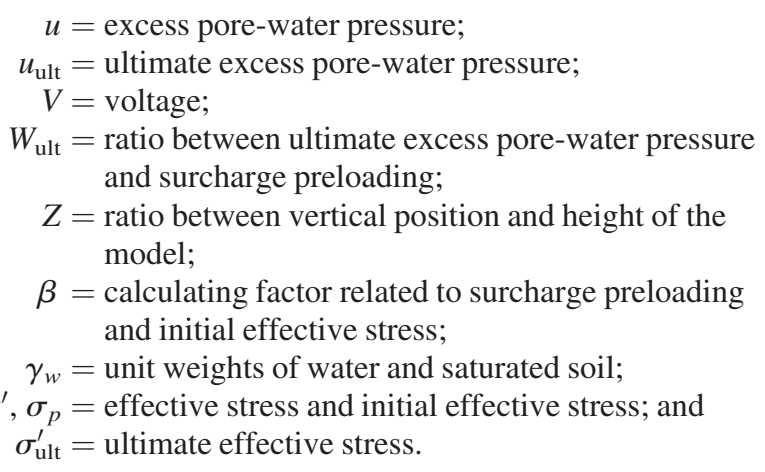

\section{References}

Abuel-Naga, H., and Pender, M. (2012). "Modified Terzaghi consolidation curves with effective stress-dependent coefficient of consolidation." Géotechnique Lett., 2(2), 43-48.

Bjerrum, L., Moum, J., and Eide, O. (1967). "Application of electro-osmosis to a foundation problem in Norwegian quick clay." Géotechnique, 17(3), 214-235.

Burnotte, F., Lefebvre, G., and Grondin, G. (2004). "A case record of electro-osmotic consolidation of soft clay with improved soil-electrode contact." Can. Geotech. J., 41(6), 1038-1053.

Cai, Y. Q., Geng, X. Y., and Xu, C. J. (2007). "Solution of one-dimensional finite-strain consolidation of soil with variable compressibility under cyclic loadings." Comput. Geotech., 34(1), 31-40.

Casagrande, L. (1949). "Electro-osmosis in soils." Géotechnique, 1(3), 159-177.

Casagrande, L. (1983). "Stabilization of soils by means of electro-osmotic state-of-art." J. Boston Civ. Eng., 69(3), 255-302.

Cherepy, N. J., and Wildenschild, D. (2003). "Electrolyte management for effective long-term electro-osmotic transport in low-permeability soils." Environ. Sci. Technol., 37(13), 3024-3030.

Davis, F. H., and Raymond, G. P. (1965). "A non-linear theory of consolidation." Géotechnique, 15(2), 161-173.

Deng, Y. F., Liu, S. Y., Zhang, D. W., and Xu, H. B. (2011). "Comparison among some relationships between permeability and void ratio." Northwestern Seismol. J., 33(B08), 64-67 (in Chinese).

Esrig, M. I. (1968). "Pore pressures, consolidation and electro-kinetics." $J$. Soil Mech. Found. Eng. Div., 94(SM4), 899-921.

Esrig, M. I., and Gemeinhardt, J. P. (1967). "Electrokinetic stabilization of an illitic clay." J. Soil Mech. Found. Div., 92(SM3), 109-128.

Fourie, A. B., Johns, D. G., and Jones, C. J. F. P. (2007). "Dewatering of mine tailings using electrokinetic geosynthetics." Can. Geotech. J., $44(2), 160-171$

Geng, X. Y., Xu, C. J., and Cai, Y. Q. (2006). "Non-linear consolidation analysis of soil with variable compressibility and permeability under cyclic loadings." Int. J. Numer. Anal. Methods Geomech., 30(8), 803-821.

Gibson, R. E., England, G. L., and Hussey, M. J. L. (1967). "The theory of one-dimensional consolidation of saturated clays." Géotechnique, 17(3), 261-273.

Gibson, R. E., Gobert, A., and Schiffman, R. L. (1990). "On Cryer's problem with large displacements and variable permeability." Géotechnique, 40(4), 627-631.

Glendinning, S., Jones, C., and Pugh, R. (2005). "Reinforced soil using cohesive fill and electrokinetic geosynthetics." Int. J. Geomech., 10.1061 /(ASCE)1532-3641(2005)5:2(138), 138-146.

Glendinning, S., Lamont-Black, J., and Jones, C. J. F. P. (2007). "Treatment of sewage sludge using electrokinetic geosynthetics." J. Hazard. Mater. 139(3), 491-499.

Hsu, T., and Tsai, T. (2015). "Combined vertical and radial consolidation under time-dependent loading." Int. J. Geomech., 10.1061/(ASCE)GM .1943-5622.0000600, 04015073.

Hu, L. M., and Wu, H. (2014). "Mathematical model of electro-osmotic consolidation for soft ground improvement." Géotechnique, 64(2), 155-164. 
Hu, L., Wu, W., and Wu, H. (2010). "Theoretical analysis and numerical simulation of electroosmosis consolidation for soft clay." Rock Soil Mech., 31(12), 3977-3983 (in Chinese).

Hu, L. M., Wu, W. L., and Wu, H. (2012). "Numerical model of electroosmotic consolidation in clay." Géotechnique, 62(6), 537-541.

Hu, L., Wu, W., and Wu, Z. (2009). "Numerical simulation of electro-osmosis in soft clay." Advances in Environmental Geotechnics: Proc., Int. Symp. on Geoenvironmental Engineering, ISGE2009, Zhejiang University Press \& Springer, Berlin, 407-412.

Indraratna, B., Rujikiatkamjorn, C., and Sathananthan, L. (2005). "Radial consolidation of clay using compressibility indices and varying horizontal permeability." Can. Geotech. J., 42(5), 1330-1341.

Jeyakanthan, V., Gnanendran, C. T., and Lo, S. C. R. (2011). "Laboratory assessment of electro-osmotic stabilization of soft clay." Can. Geotech. J., 48(12), 1788-1802.

Jones, C. J. F. P., et al. (2008). "Recent research and applications in the use of electro-kinetic geo-synthetics." Proc., 4th European Geosynthetics Conf., Sep. 1-3, 2008, Heriot-Watt University, Edinburgh, U.K., Keynote Paper, No. 329.

Lefebvre, G., and Burnotte, F. (2002). "Improvement of electro-osmotic consolidation of soft clays by minimizing power loss at electrodes." Can. Geotech. J., 39(2), 399-408.

Lekha, K., Krishnaswamy, N., and Basak, P. (2003). "Consolidation of clays for variable permeability and compressibility." J. Geotech Geoenviron. Eng., 10.1061/(ASCE)1090-0241(2003)129:11(1001), 1001-1009.

Li, Y., Gong, X. N., Lu, M. M., and Guo, B. (2010). "Coupling consolidation theory under combined action of load and electro-osmosis." Chin. J. Geotech. Eng., 32(1), 77-81 (in Chinese).

Lo, K. Y., Ho, K. S., and Inculet, I. I. (1991). "Field test of electroosmotic strengthening of soft sensitive clay." Can. Geotech. J., 28(1), 74-83.

Meegoda, N. J., King, I. P., and Arulanandan, K. (1989). "An expression for permeability of anisotropic granular media." Int. J. Numer. Anal. Methods Geomech., 13(6), 575-598.

Micic, S., Shang, J. Q., Lo, K. Y., Lee, Y. N., and Lee, S. W. (2001). "Electro-kinetic strengthening of a marine sediment using intermittent current." Can. Geotech. J., 38(2), 287-302.

Mitchell, J. K., and Soga, K. (2005). Fundamentals of soil behavior, 3rd Ed., John Wiley \& Sons, New York.

Shang, J. Q. (1998). "Electroosmosis-enhanced preloading consolidation via vertical drains." Can. Geotech. J., 35(3), 491-499.

Su, J., and Wang, Z. (2003). "The two-dimensional consolidation theory of electro-osmosis." Géotechnique, 53(8), 759-763.

Walker, R., and Indraratna, B. (2006). "Vertical drain consolidation with parabolic distribution of permeability in smear zone." $J$. Geotech. Geoenviron. Eng., 10.1061/(ASCE)1090-0241(2006)132: 7(937), 937-941.
Walker, R., Indraratna, B., and Rujikiatkamjorn, C. (2012). "Vertical drain consolidation with non-Darcian flow and void-ratio-dependent compressibility and permeability." Géotechnique, 62(11), 985-997.

Wan, T. Y., and Mitchell, J. K. (1976). "Electro-osmotic consolidation of soils." J. Geotech. Eng. Div., 102(5), 473-491.

Wu, H., and Hu, L. M. (2012). "Analytical models of the coupling of vacuum preloading and electro-osmosis consolidation for ground stabilization." J. Tsinghua Univ., 52(2), 182-185 (in Chinese).

$\mathrm{Wu}, \mathrm{H}$., and $\mathrm{Hu}$, L. M. (2013). "Analytical solution for axisymmetric electro-osmotic consolidation." Géotechnique, 63(12), 1074-1079.

Wu, H., and Hu, L. M. (2014). "Microfabric change of electro-osmotic stabilized bentonite." Appl. Clay Sci., 101, 503-509.

Wu, H., Hu, L. M., and Wen, Q. B. (2015a). "Electro-osmotic enhancement of bentonite with reactive and inert electrodes." Appl. Clay Sci., 111, $76-82$.

Wu, H., Hu, L., and Zhang, G. (2016). "Effects of electro-osmosis on the physical and chemical properties of bentonite." J. Mater. Civ. Eng., 10 .1061/(ASCE)MT.1943-5533.0001572, 06016010.

Wu, H., Hu, L. M., Zhang, L., and Wen, Q. B. (2015b). "Transport and exchange behavior of ions in bentonite during electro-osmotic consolidation." Clays Clay Miner., 63(5), 395-403.

Xie, K. H., Xie, X. Y., and Jiang, W. (2002). "A study on one-dimensional nonlinear consolidation of double-layered soil." Comput. Geotech., 29(2), 151-168.

Xu, W., Liu, S. H., Wang, L. J., and Wang, J. B. (2011). “Analytical theory of soft ground consolidation under vacuum preloading combined with electro-osmosis." J. Hohai Univ., 30(2), 169-175 (in Chinese).

Yoshida, H., Kitajyo, K., and Nakayama, M. (1999). "Electroosmotic dewatering under A.C. electric field with periodic reversals of electrode polarity." Drying Technol., 17(3), 539-554.

Yuan, J., and Hicks, M. A. (2013). "Large deformation elastic electroosmosis consolidation of clays." Comput. Geotech., 54, 60-68.

Zhan, L., Zhan, X., Feng, Y., and Chen, P. (2016). "Electrokinetic dewatering of sewage sludge with fixed and moving electrodes: Attenuation mechanism and improvement approach." J. Environ. Eng., 10.1061/ (ASCE)EE.1943-7870.0001016, 04015058.

Zhou, Y. D., Deng, A., and Wang, C. (2013). "Finite-difference model for one-dimensional electro-osmotic consolidation." Comput. Geotech., 54, $152-165$.

Zhu, G., and Yin, J. (2012). "Analysis and mathematical solutions for consolidation of a soil layer with depth-dependent parameters under confined compression." Int. J. Geomech., 10.1061/(ASCE)GM.1943-5622 $.0000152,451-461$.

Zhuang, Y., and Wang, Z. (2007). "Interface electric resistance of electroosmotic consolidation." J. Geotech. Geoenviron. Eng., 10.1061 /(ASCE)1090-0241(2007)133:12(1617), 1617-1621. 